\title{
Aftermath of 9.0/2004 and the tsunami
}

\author{
Sri Lanka Journal of Child Health, 2005; 34: 1-2
}

(Key words: tsunami, aftermath)

In the morning of that momentous day of the $26^{\text {th }}$ of December 2004, the world was rocked by a natural disaster of unprecedented fury. An under-sea earthquake off the coast of Sumatra, of incredible force measuring 9.0 on the open ended Richter scale, set off a tsunami wave that devastated many countries of the South Asian region. The earthquake itself caused havoc around its epicentre while the tsunami set in motion a trail of destruction in the coastal areas, scattered thousands of kilometres away. To say the least, the effects were widespread and devastating. Sri Lanka was one of the countries worst affected by this quirk of Mother Nature. The coastal belt of virtually a two third of the island was inundated. It took only just a few minutes for this inexplicable action of nature to be completed. Thousands died while hundreds of thousands were literally left with nothing except the clothing on their bodies. In short, it was a nightmare beyond all conceivable portrayal.

A very large number of children in Sri Lanka were affected in many different ways. Many died in the grip of the direct tsunami wave while a considerably larger number were orphaned. Others lost everything that they had. A significant number of them from the metropolis and other areas of the country, who were either visiting the area or were on holiday, were brusquely affected by the relentless scourge of the sea coming inland.

In our motherland, there are many tales of heroism, many an anecdote of selfless sacrifice, heartrending stories of inexplicable personal tragedy and incredible narratives of individual courage under the most trying of circumstances. The country initially reeled under the impact. The shock of the trail of annihilation paralysed the nation. Then, within a matter of a relatively short time, many different agencies and individuals rallied round, took very deep breaths and literally waded in to help those affected. The media, especially the electronic media and the Information Communication Technology (ICT) sectors, set up a network of information gathering and dissemination that has, in retrospect, been hailed as a "world-class" effort. Not to be outdone, the simple village folk of the affected areas showed that they are a community for all seasons by sharing what little they had with those who had lost almost everything. In many other areas of the country, large numbers of our fellow men and women contributed their mite to the relief effort. People of all walks of life gave whatever they could and that allimportant energy to help the victims. The nation rose up as a whole in this, our greatest hour of need.

However, it was apparent that the work that had to be undertaken to rebuild the battered nation was indeed a daunting task. Among the many different intricacies of the enormous problems that were confronted, one was very special. That was the host of possible problems involving affected children.

Virtually the day after the tragedy, the Sri Lanka College of Paediatricians met in emergency session and tried its best to formulate a plan of action to help these unfortunate children. Two things were needed. One was a concrete sketch to look after the physical and mental problems of the affected children. The other was to get hold of the funds required to put the plan into action. We had the expertise at our disposal to attend to the former. The funds had to be obtained from charities, fund-raising activities and appeals.

The College appointed a Task Force to attend to the details of the work to be undertaken. All Fellows and Members of the College willingly and unstintingly supported this Task Force. The immediate concerns regarding the affected children were the fear of the occurrence of epidemic diseases in the camps for displaced persons, the safety and welfare of separated children and the myriad of problems of the unaccompanied minors. The College worked very closely with the Ministry of Health, The Department of Probation and Childcare, The National Child Protection Authority (NCPA), The Family Health Bureau, The UNICEF and The Ministry of Justice, in all their endeavours.

The College advised the authorities on the details of nutrition in the immediate rescue and rehabilitation phases. Working closely with the NCPA we took steps to ensure the safety of children and unaccompanied minors. The College advice was 
sought by, and readily given to, the Ministry of Justice regarding standards for fostering of affected children. The College advice was also sought by and given to the Ministry of Health on the National Mental Health Policy for tsunami affected children. The College organized a special lecture followed a few days later, by a workshop on Psychological Rehabilitation of affected children. Specialists in the field from Israel and the United Kingdom conducted these activities.

What are the plans of the Task Force and the College for the future? We are in the process of organizing a sponsorship scheme, to be called the "Rainbow Children's Trust", in collaboration with the People's Bank, to enable interested parties from here and abroad to provide financial sponsorship for affected children. This was in response to many inquiries that would satisfy the precise personal need of the sponsors to help specifically identified children.

The College would be instrumental in organizing a "twinning programme" whereby affected schools would be linked to specified schools from abroad. Hopefully, the local counterparts would be helped by the children in the schools in other countries of the world and maybe, just maybe, those children from abroad would be able to visit our land and develop a long-standing camaraderie with our children. The College is thinking of building specially equipped "Rainbow Community Centres for Children and Adolescents", perhaps 4 or 5 in number, which would be drop-in centres. At these centres, they would be exposed to activities, skills development, vocational training, health education and outreach clinics, serving medical and psychological needs.

The recurring theme of the rainbow in the plans of the College is certainly not a coincidence. It is envisaged that the rainbow would be a colourful symbol that would signify hope to all those children who have lost virtually everything. It is also hoped that the rainbow would imply that there are people who care in this great family of the Homo sapiens.
A handbook on management of children in disaster affected situations and a pre-Congress workshop on disaster management will be a reality in the near future.

In the aftermath of the disaster the College would have to ensure equitable distribution of the rehabilitation efforts that it undertakes. It would also be imperative that careful monitoring and evaluation of our efforts be undertaken to make sure that the goals that we have set upon ourselves are being achieved. It would be a continuing effort which would stretch into quite a few long years into the future. This would definitely extend well beyond the term of office of the present College administration.

Tsunami is a Japanese word for a "harbour wave". From an entirely different perspective, another Japanese word for crisis has two connotations. They are danger and opportunity. Even in the midst of calamities there are likely to be windows of opportunity. We have recognized the dangers of natural disasters. For a nation that has so far been fortunate in being shielded from massive natural disasters, this has been a learning experience, albeit one that would be looked upon as an appalling one. We have to learn the lessons that nature has attempted to teach us. This is especially important, as, according to the latest information, there is an entirely new fault that has developed in the Australasian tectonic plate, uncomfortably close to Sri Lanka. That makes us that much more vulnerable to earthquakes. The catastrophe that befell our beloved land is perhaps a chance to do all we can to mitigate the effects of another natural disaster. It is also an opportunity to rebuild and rise from the ashes like the proverbial phoenix. Towards these ends, one hopes that the Sri Lanka College of Paediatricians would be a flag-bearer and a beacon to follow.

\section{B J C Perera} Joint Editor 